ROLE OF MAGNETIC RESONANCE IMAGING IN THE EVALUATION OF SONOGRAPHICALLY INDETERMINATE ADNEXAL MASSES

Mohamad Hamdy Mahmoud Zahran, *Tamer Hanafy Mahmoud, Amal Shawky Ismail, Zeinab Salah El Din Ibrahim

Department of Radiodiagnosis and Intervention,*Department of Obstetrics and Gynecology, Faculty of Medicine, Alexandria University

\begin{abstract}
Introduction
Determining the nature of a sonographically indeterminate adnexal masses has great clinical importance, decisions regarding the type and extent of surgery necessary and who should perform this surgery depend on this judgment. An adnexal mass is defined as indeterminate on ultrasonography when it cannot be exactly placed into either the benign or malignant category, even after Doppler assessment, or one for which the site of origin from the ovary, uterus or another pelvic structure, remains to be established Pelvic Ultras Pelvic Ultrasongaph in clinically suspected adnexal masses, However, sonography is limited by: it's low specificity for the diagnosis of benignity, leading to as many as $20 \%$ of adnexal masses being classified as indeterminate. For women with theses indeterminate masses MR Imaging provides excellent contrast resolution, resulting in accurate tissue characterization and improved anatomic delineation.

The ACR O-RADS MRI committee developed an evidenced-based risk stratification scoring system based on existing diagnostic efficacy studies, and validated by an ongoing prospective multicenter clinical trial.
\end{abstract}

\section{Aim of the work}

The aim of this work was to assess the ability of MRI to characterize sonographically indeterminate adnexal masses.

\section{Subject and methods}

This study was conducted on 26 patients their ages ranged between 15 and 58 years. Each patient was subjected to:

-Adequate history taking.

-Thorough clinical examination

-Ultrasound examination(TAUS /TVUS approach) - Pelvic MR imaging

-Histopathological analysis whenever indicated _- Statistical analysis.

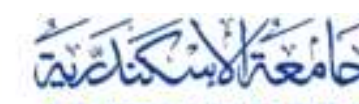 \\ ALEXANDRRIA \\ $2021 \odot$ Alexandria Faculty of Medicine}

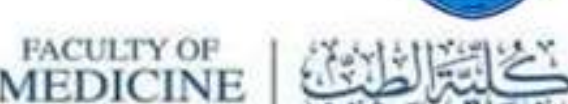

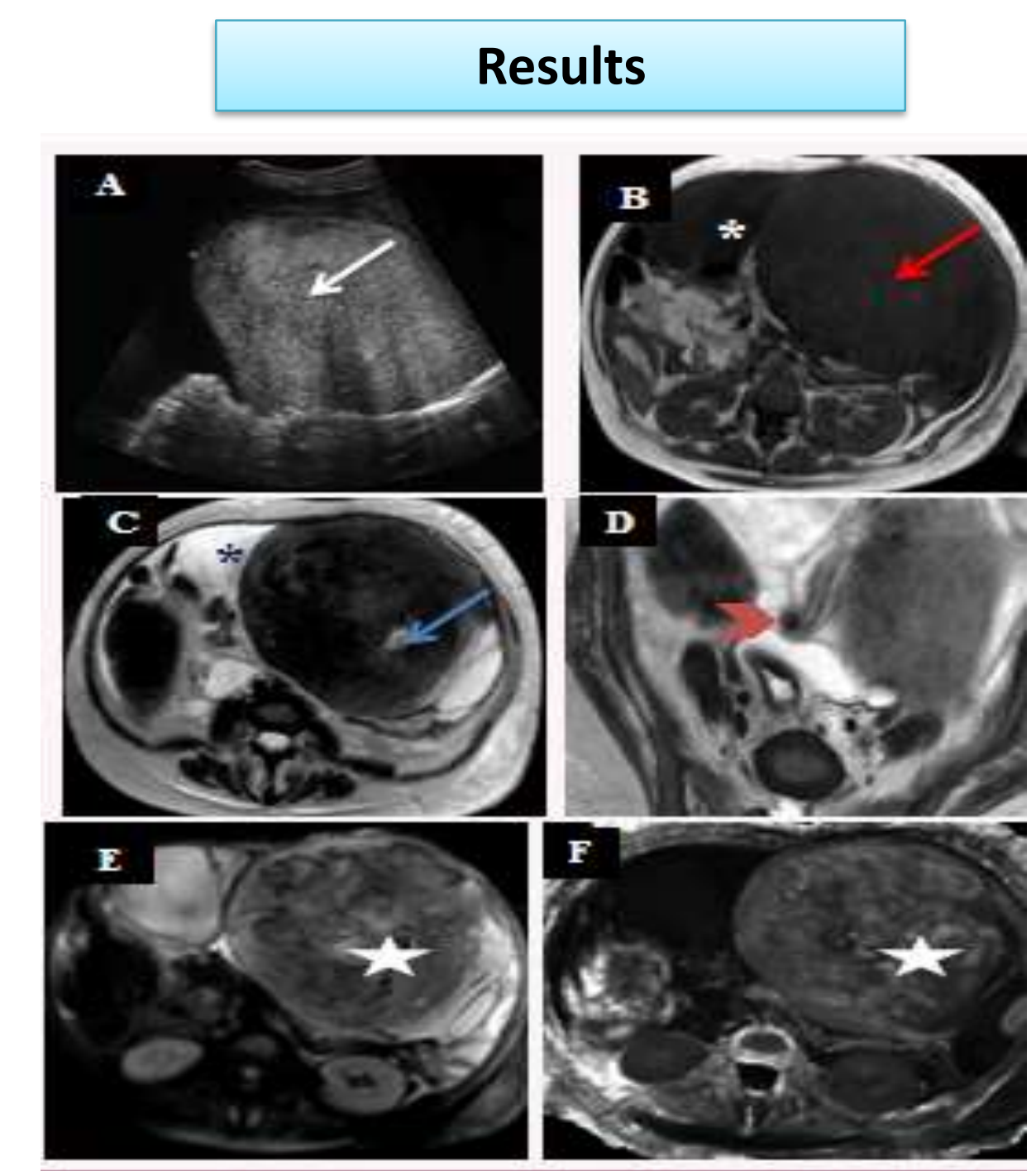

Case (1):

Trans-abdomial US: Sizable pelvi-abdominal hypo echoic solid mass lesion moderate ascites (A).

MR imaging: Axial T1WI (B) andT2WI (C) : sizable pelvi-abdominal right adnexal solid mass lesion showing $\mathrm{T} 1$ and T2 hypo intense signal with areas of degenerations., coronal T2WI (D) the lesion is seen deviated to the left side with twisted pedicle associated with marked septated ascites. DWI (E) and ADC map (F): No diffusion restriction.

Features of benign looking right adnexal hormonal secreting sex cord stromal tumorn mostly fibroma associated with marked septated ascites with no pathologically enlarged, pelvic LN ( Meg s syndrome). Which was confirmed by pathology.

In this case : Solid lesion of low signal on T2 (C)and DWI (E)and wa assigned

as MRI ORADS score 2 .Marked T2 hypo intense signal in MRI helped in confirming the fibrous nature of the lesion
Table (1): Distribution of patients according to origin of the lesion

\begin{tabular}{|c|l|c|c|}
\hline \multicolumn{2}{|c|}{ Origin of the lesion } & No. of patients & $\%$ \\
\hline By & Determinate origin & 21 & 80.8 \\
\hline \multirow{3}{*}{ Ultrasnography } & Indeterminate origin & 5 & 19.2 \\
\hline \multirow{3}{*}{ By MRI } & Ovarian & 19 & 73.1 \\
\cline { 2 - 4 } & Extra-ovarian & 7 & 26.9 \\
\cline { 2 - 4 } & Fallopian tube & 2 & 7.7 \\
\cline { 2 - 4 } & Broad ligament & 1 & 3.8 \\
\cline { 2 - 4 } & Uterine & 1 & 3.8 \\
\hline & Others & 3 & 11.5 \\
\hline
\end{tabular}

Table (2): Distribution of the studied adnexal lesions according to MRI O-RADS risk stratification

\begin{tabular}{|c|c|c|}
\hline MRI O-RADS risk stratification & $\begin{array}{c}\text { No. of } \\
\text { patients }\end{array}$ & $\%$ \\
\hline $\begin{array}{c}\text { O-RADS 1 } \\
\text { (Normal ovaries) }\end{array}$ & 1 & 3.8 \\
\hline $\begin{array}{c}\text { O-RADS 2 } \\
\text { (Low-risk of malignancy almost certainly benig) PPV } \\
<0.5 \% \text { for malignancy) }\end{array}$ & 12 & 46.1 \\
\hline $\begin{array}{c}\text { O-RADS 3 } \\
\text { (Low-risk of malignancy,PPV 5\% for malignancy) }\end{array}$ & 3 & 11.5 \\
\hline $\begin{array}{c}\text { O-RADS 4 } \\
\text { (Intermediate risk,PPV for 50\%malignancy) }\end{array}$ & 6 & 23.1 \\
\hline $\begin{array}{c}\text { O-RADS 5 } \\
\text { (High risk, PPV 90\% of malignancy) }\end{array}$ & 4 & 15.4 \\
\hline
\end{tabular}

\section{Conclusion}

MR imaging can further assess indeterminate or incompletely evaluated adnexal lesions discovered on ultrasound with a high sensitivity and specificity for the diagnosis of malignancy.

Correctly classifying an adnexal mass as benign or borderline allow Correctly classifing an ads oxal mass as benign or borderline allow MRI -ORADS risk stratification score system has important role in pre MRI-ORADS risk stratification score system has important role in preoperative assessment of indeterminate adnexal lesions and avoidance of unnecessary radical surgical approach in case of benign or borderline lesions. 